Pobrane z czasopisma Annales I - Philosophy and Sociology http://philosophia.annales.umcs.pl Data: 26/04/2023 15:36:46

DOI: $10.17951 / i .2017 .42 .2 .61$

A N N A LES

UNIVERSITATIS MARIAE CURIE-SKŁODOWSKA

LUBLIN - POLONIA

VOL. XLII, 2

SECTIO I

2017

\title{
El origen del conocimiento según Ramón Turró como comienzo psicológico de la epistemología kantiana
}

Pochodzenie wiedzy jako psychologicznego początku epistemologii kantowskiej w ujęciu Ramóna Turro

\section{INTRODUCCIÓN}

La gnoseología y la epistemología se preguntan por el conocimiento humano. El filósofo y biólogo catalán Ramón Turró i Darder, desde su extensa formación en biología, amplió la pregunta al origen del conocimiento en todos los organismos cognoscentes. No es ningún secreto que, para responder a esta pregunta, Turró propuso una teoría en la que el conocimiento se origina en la necesidad que tienen los organismos por calmar el hambre o, dicho de otra manera, por la experiencia de satisfacción del impulso trófico'1.

Del 1910 al 1911, Turró presentó sus artículos sobre el hambre, los cuales se publicaron en Francia en el "Journal de Physiologie nórmale et pathologique" y en Alemania en los números 44 y 45 de la "Zeitschrift für Psychologie und Sinnespshysiologie", para ser ampliados en 1911 bajo el título Ursprung der Erkenntnis. Die physiologische Psychologie des Hungers, obra editada por J. A. Barth en Leipzig. Un año más tarde, se publicarían como libro en catalán, en francés en 1914 y en castellano en 1916, con el nombre de Orígenes del conocimiento: el hambre ${ }^{2}$.

1 R. Turró, Orígens del coneixement: la fam, Barcelona 1912; idem, La base trófica de la inteligencia, Serie I, T. IV, Madrid 1918; idem, Orígenes del conocimiento: el hambre, Madrid 1921.

2 En este artículo hemos seguido la edición de 1921 publicada por la editorial Atenea 
En estos textos, Turró quiere explicar la facultad de conocer partiendo de los más básicos impulsos biológicos. Pero eso no quiere decir, en ningún caso, que sus teorías sean absolutamente materialistas o que haga depender todo de la actividad nerviosa del sujeto. En efecto, si así fuera, no se podría garantizar la validez objetiva del conocimiento. Turró, igual que Kant, sostiene la necesidad de que tengamos un principio de causalidad, ya que, sin él, no podemos explicar el conocimiento de lo real. Ahora bien, su explicación no va a ser la de Kant, pero tampoco la de los racionalistas o la de los empiristas. Para Turró:

La razón especulativa puede explicarse la referencia externa concibiendo que la causalidad le ha sido dada a la inteligencia originalmente; mas la razón rebelde y libre puede dejar de concebirlo así. Se preguntará entonces: ¿cómo se explica que el conocimiento de lo real se presuponga a la experiencia externa? ${ }^{3}$

Turró no va derivar el conocimiento solamente de las sensaciones o de las intuiciones como diría Kant, al igual que éste, entenderá que "las intuiciones sin conceptos son ciegas"4. En ambos autores el ser humano no es pasivo, sino que actúa para satisfacer sus necesidades. Turró encontrará la necesidad primordial, en la satisfacción de la necesidad que tenemos todos los organismos de alimentarnos. Justamente, será el hambre la necesidad básica que ponga en marcha todo el proceso de interpretación de los datos brutos de los sentidos, lo que en terminología kantiana podemos llamar "síntesis originaria". Será pues, como resultado de este proceso hermenéutico originario, que los datos de los sentidos son interpretados como reales por el organismo.

Asi mismo, como parte integrante de este proceso, aparece la experiencia del espacio indisolublemente ligada a los movimientos del cuerpo. Siendo gracias a la operatoriedad, es decir, a la interacción física con objetos, por lo que los organismos llegan a ser conscientes de las sensaciones, y éstas, a su vez, hacen consciente al organismo de que es independiente de los objetos, es decir, lo que Kant llama "sentido interno o apercepción empírica".

Comienza así, una relación entre sensibilidad y operatoriedad necesaria para que se produzca algún grado de concienciay, con esta, el conocimiento. Conocimiento de que el organismo es diferente de los objetos que le rodean, y conocimiento de los objetos externos o substancias, como las denomina Turró. Así pues, no es casual que los organismos cognoscentes sean activos, y lo son porque

(M. Siguan, Ideas psicológicas en la obra de Ramón Turró, "Revista de Historia de la Psicología" 1980, núm. 3-4, pp. 323-352).

R. Turró, Orígenes del conocimiento..., p. 215.

4 E. Kant, Crítica de la razón pura, Madrid 2005, p. XVIII.

5 Ibídem, p. 94. 
necesitan desplazarse para encontrar los nutrientes, o en términos de Turró, las sustancias que les faltan.

\section{EL IDEALISMO DE KANT Y EL REALISMO DE TURRÓ}

\section{Como dice Turró en las últimas páginas del capítulo V:}

Concíbase lo real subjetiva u objetivamente o asúmase bajo una concepción monística, ello es que, independientemente del problema metafísico, existe el problema de los orígenes de ese conocimiento. Son dos cosas muy distintas la una y la otra, ya que al proponernos averiguar qué sea o en qué consiste lo real, no nos proponemos averiguar cómo y de qué manera hemos llegado a saber que fuera de la propia conciencia hay algo que subsiste y permanece como tal, aun cuando no sea pensado ni fuere entendido ${ }^{6}$.

Muchas de las objeciones que se hacen a la epistemología kantiana vienen de no entender, o de no querer escuchar, una de las premisas que encontramos al comienzo de la Crítica de la razón pura, es decir:

No hay duda alguna de que todo nuestro conocimiento comienza con la experiencia. Pues ¿cómo podría ser despertada a actuar la facultad de conocer sino mediante objetos que afectan a nuestros sentidos y que ora producen por sí mismos representaciones, ora ponen en movimiento la capacidad del entendimiento para comparar estas representaciones, para enlazarlas o separarlas y para elaborar de este modo la materia bruta de las impresiones sensibles con vistas a un conocimiento de los objetos denominado experiencia? Por consiguiente, en el orden temporal, ningún conocimiento precede a la experiencia y todo conocimiento comienza con ella.

Pero, aunque todo nuestro conocimiento empiece con la experiencia, no por eso procede todo él de la experiencia. En efecto, podría ocurrir que nuestro mismo conocimiento empírico fuera una composición de lo que recibimos mediante las impresiones y de lo que nuestra propia facultad de conocer produce (simplemente motivada por las impresiones) a partir de sí misma. En tal supuesto, no distinguiríamos esta adición respecto de dicha materia fundamental hasta tanto que un prolongado ejercicio nos hubiese hecho fijar en ella y nos hubiese adiestrado para separarla?.

Así pues, Kant desarrolla una teoría sobre el origen lógico del conocimiento sin la cual no se puede preservar la universalidad fenoménica de la ciencia, pero tal cosa no resulta incompatible con que todo conocimiento comience en la experiencia y, en particular, como señala el profesor Turró, en la experiencia trófica.

Como dice Miguel de Unamuno en el prólogo que hace al libro de Turró "Pero téngase en cuenta que la tesis de este libro es una tesis de psicología más que de lo llamado teoría del conocimiento". Y "la crítica de Kant no es psicología, sino

6 R. Turró, Orígenes del conocimiento..., pp. 216-217.

7 I. Kant, op. cit., pp. 27-28.

8 M. de Unamuno, Prólogo, [en:] R. Turró, Orígenes del conocimiento. El hambre (5-16), Madrid 1921, p. 8. 
lógica. Mas no lógica formal [...], no lógica analítica, sino lógica sintética"9. Lo que en la secuencia psicológica o temporal va al final, en el razonamiento lógico va al principio y viceversa, o, dicho de otra manera una cosa es el comienzo psicológico y otra el origen lógico.

También distingue Unamuno ambos tipos de conocimiento en el segundo capítulo de Del sentimiento trágico de la vida en los hombres y en los pueblos ${ }^{10}$ :

Mas es menester distinguir aquí entre el deseo o apetito de conocer, aparentemente y a primera vista, por amor al conocimiento mismo, entre el ansia de probar del fruto del árbol de la ciencia, y la necesidad de conocer para vivir. Esto último, que nos da el conocimiento directo e inmediato, y que en cierto sentido, si no pareciese paradójico, podría llamarse conocimiento inconsciente, es común al hombre con los animales, mientras lo que nos distingue de estos es el conocimiento reflexivo, el conocer del conocer mismo ${ }^{11}$.

Por consiguiente, la epistemología de Kant no hace referencia al origen del conocimiento animal y, por ende, al origen empírico del conocimiento, sino al conocimiento científico con pretensión de universalidad y necesidad. Incluso en este caso, toma la precaución de restringirlo a aquello que puede ser conocido, es decir, al ámbito fenoménico, con el fin de evitar equívocos como los expuestos en la antinomia o en los paralogismos ${ }^{12}$.

Entendido de esta manera, las teorías de Turró explicarían cómo comienza el conocimiento en la experiencia; mientras que la epistemología de Kant, haría referencia a los mecanismos racionales que dotan de universalidad y necesidad al conocimiento científico. El conocimiento propio del ser humano se diferencia del conocimiento animal en que aquél es capaz de extraer los principios generales comenzando, en el orden temporal, por un proceso inductivo y extrayendo de él, aunque parezca extraño, una deducción lógica, la cual se constituye en lo primero en el orden lógico. En efecto, mediante la inducción llegamos a un principio que se transforma en deductivo porque se convierte en necesario para que el conocimiento sea universal. Kant dota de universalidad al conocimiento a fuerza de sellar todos los resquicios por los que puede colarse lo empírico, para que, de esta manera, los juicios sintéticos puedan ser conocidos a priori.

9 M. García Morente, La filosofía de Kant: una introducción a la filosofía, Madrid 1975, p. 35.

10 Los capítulos I y II de Del Sentimiento trágico de la vida de Miguel de Unamuno están íntimamente relacionados con las ideas expuestas en este artículo y con el pensamiento de Ramón Turró acerca del origen trófico del conocimiento. A este respecto, se recomienda leer el estudio que realiza Antonio M. López Molina incluido en su edición de esta obra, titulado Filosofía como reflexión sobre el sentimiento trágico de la vida ([en:] M. de Unamuno, Del sentimiento trágico de la vida en los hombres y en los pueblos, edición de A. M. López Molina, Madrid 2006, pp. 19-53).

11 Ibidem, pp. 72-73.

12 E. Kant, op. cit. 
Pobrane z czasopisma Annales I - Philosophy and Sociology http://philosophia.annales.umcs.pl Data: 26/04/2023 15:36:46

El origen del conocimiento según Ramón Turró como comienzo psicológico...

65

Tras esta salvedad fundamental, no podemos dejar de establecer ciertas analogías entre las teorías de ambos autores, como se apreciará en algunos puntos de este artículo.

\section{EL ORIGEN TRÓFICO DEL CONOCIMIENTO}

\section{La excitación trófica y la realidad}

Turró pensaba que la función nutricional es lo primero y fundamental para la vida, por lo que centró sus investigaciones en el impulso trófico. A este respecto, Unamuno dice que "el conocimiento se nos muestra ligado a la necesidad de vivir y de procurarse sustento para lograrlo"13. El mismo Unamuno nos recuerda que este impulso primigenio se parece a lo que Spinoza llamó conatus, ya que "Cada cosa se esfuerza, cuanto está a su alcance, por perseverar en su ser"14.

Según Turró, en oposición a la concepción periferalista, "la sensación que se localiza en el estómago no debe ser confundida con la del hambre, dado que ésta subsiste o reaparece independientemente de aquélla"15. Y es que Turró conocía la existencia del "medio interno" por los estudios de Claude Bernard. En 1879, Claude Bernard dijo que "la estabilidad del medio interno es un requisito para la supervivencia de los organismos" ${ }^{16}$. Turró, en el primer capítulo de Orígenes del conocimiento: el hambre, expresa, con toda claridad, que "la causa determinante del hambre reside en laspérdidas que experimenta el medio interno a consecuencia de la nutrición celular"17.

Según las propias palabras de Turró:

La excitación trófica [...] acabará por estallar en la conciencia a manera de un clamor en que se acusa una necesidad que no puede remediar esa sensibilidad silenciosa y obscura que hasta entonces había mantenido el organismo a expensas de sí mismo. Así es como se determina la aparición de la sensación del hambre ${ }^{18}$.

Por tanto, la excitación trófica sería algo así como una anticipación de la percepción, es decir, de aquellas representaciones de las que tenemos conciencia, ya que para que algo pueda ser conocido, lo primero es creer que hay algo. Estas representaciones pueden existir o no, eso ahora no nos interesa, ahora sólo nos

\footnotetext{
M. de Unamuno, Del sentimiento trágico..., p. 93.

B. Spinoza, Ética, edición, traducción y notas por V. Peña, Madrid 2009, p. 203.

R. Turró, Orígenes del conocimiento..., p. 22.

E. Martín Cuenca, Fundamentos de fisiología, Madrid 2006, p. 4.

R. Turró, Orígenes del conocimiento..., p. 21.

18 Ibídem, p. 41.
} 
importa su realidad, esto es, en terminología kantiana, su contenido quiditativo, la quididad, la essentia, la res, la realitas phaenomenon.

\section{La existencia}

No obstante, según Turró, todos los organismos comparten la creencia en que lo que perciben existe realmente, ya que el alimento representa "aquello que nos proporciona lo que de real nos faltapara seguir viviendo"19.

Para fundamentar esta idea se apoya en la teoría de la visión de Helmholtz. Para este autor, siguiendo los razonamientos del propio Turró, "las sensaciones son signos ininteligibles mientras no sean interpretados dándoles una significación de que carecen por sí mismos"20. Estas sensaciones "suministran a la inteligencia lo que Kant llamaba, siguiendo la tradición aristotélica, la materia del conocimiento"21. Por tanto, las sensaciones por sí solas no nos dicen si hay algo fuera de nosotros que las provoque. Pero, en ese caso, ¿cómo objetivamos las impresiones? Mediante un proceso inductivo.

La exteriorización es la obra de un proceso inductivo, o de un razonamiento como decía Helmholtz, cuyo mecanismo es indispensable investigar para poder formarnos cargo de cómo es que estamos tan profundamente persuadidos de que lossentidos no nos engañan y se adaptan siempre a una realidad viviente ${ }^{22}$.

Pues bien, la clave de la creencia en la existenciaes que establecemos una causa entre el alimento (lo real que nos falta) y la necesidad de conseguirlo en virtud del movimiento, el cual, a su vez, conlleva tener que superar ciertas resistencias. Como dice Turró: "Sabemos que lo real existe como algo, porque nos nutre; sabemos que es exterior porque por la experiencia motriz advertimos que esto es lo que impresiona nuestros sentidos"23. Por tanto, se establece una relación sucesiva, que es percibida como necesaria, entre el alimento (lo real), su búsqueda (la experiencia motriz) y la saciedad del hambre (necesaria para seguir viviendo). También Unamuno dice que "Los seres que parecen dotados de percepción, perciben parapoder vivir, y sólo en cuanto para vivir lo necesitan, perciben" ${ }^{24}$. De ahí que confiera tanta importancia a la función trófica, hasta el punto de establecer que el mundo sensible "es hijo del hambre"25.

\footnotetext{
Idem, La base trófica..., p. 124.

Idem, Orígenes del conocimiento..., p. 227.

Ibidem.

Ibídem, p. 229.

Ibídem, p. 347.

M. de Unamuno, Del sentimiento trágico..., p. 93.

Ibidem, p. 95.
} 
Decíamos hace un momento, que los organismos para conseguir el alimento van a tener que desplazarse, lo cual implica vencer una serie de resistencias. La resistencia es considerada una fuerza (dynamis) y es, justamente la fuerza, la que determina la existencia del objeto. "Donde hay acción y, consiguientemente, actividad y fuerza, hay también sustancia" 26 . Cuando el organismo se desplaza realiza un esfuerzo motor, debido a la oposición que las cosas externas a su propio cuerpo le someten. O, dicho de otra manera, a los obstáculos que se encuentra por el camino. Estos obstáculos, en tanto que son sorteados, o pretenden serlo, son conocidos. Como dice Fuentes:

En resolución, las cosas conocidas existen, y asimismo existen las relaciones causales entre ellas, como se pone fehaciente mente de manifiesto, respectivamente, en la experiencia de resistencia que ellas oponen al esfuerzo motor voluntario y al impulso desiderativo que moviliza dicho esfuerzo y en la experiencia del vencimiento de dicha resistencia efectuada por este esfuerzo motor ${ }^{27}$.

Llegados a este punto, intuimos que el espacio también se va a dar en este mismo proceso, es decir, el espacio aparece cuando las percepciones sensoriales y los movimientos operatorios del organismo son puestos en relación. "Eso es así porque los movimientos del cuerpo tienen una dirección y acaban en una postura o en un contacto con algo exterior, determinando, por consiguiente, una localización”28.

Nada más indiscutible que lo exterior ejerza una acción constante sobre nuestro organismo y nuestros aparatos sensoriales; más la vida intelectiva no comienza con esa acción; se inicia en el instante mismo en que se reacciona sobre ese medio con el clamor trófico y las impulsiones ciegas al movimiento; fráguanse entonces complicadísimos procesos de adaptación a este medio y es en virtud de esas adaptaciones que adquirimos la conciencia de lo real, de la causa, del espacio ${ }^{29}$.

\section{El conocimiento}

De esta particular dialéctica entre la ausencia y la presencia, entre el hambre y la saciedad, entre lo vacío y lo lleno, surge el conocimiento. Necesariamente, el organismo tiene que desarrollar un cierto conocimiento de su entorno que le permita superar los obstáculos y vencer las resistencias que encuentra en su camino hacia el alimento. En efecto, los organismos heterótrofos se ven continuamente acosados por la necesidad de satisfacer sus apetitos, en especial, su impulso trófico.

26 E. Kant, op. cit., p. 165

27 J.B. Fuentes, La Teoría del origen trófico del conocimiento deRamón Turró: Un ensayo sobre su trasfondo histórico-filosóficoy sus posibilidades de desarrollo teórico en el sentido de una concepción (neo)aristotélica de la vida, "Psychologia Latina" 2010, núm. 1, p. 46.

28 M. Siguan, op. cit., p. 341.

29 T. Turró, Orígenes del conocimiento..., p. 356. 
Ante esa necesidad, no les queda más remedio que explorar su mundo circundante para obtener el preciado alimento. Esa exploración de aquello que les rodea y que toman por real, implica necesariamente algún tipo de movimiento en el que se guiarán por las "señales" que le vengan del alimento, olores orastros bioquímicos de los nutrientes. De esta manera, el conocimiento tanto del mundo externo, como la conciencia del propio cuerpo, comienza con la experiencia trófica ${ }^{30}$.

El conocimiento así entendido, es necesariamente operatorio, es decir, se produce en los movimientos que el sujeto tiene que realizar para alcanzar sus objetivos. En palabras de Unamuno:

Con términos en que la concreción raya acaso en grosería, cabe decir que el cerebro, en cuanto a su función, depende del estómago. En los seres que figuran en lo más abajo de la escala de los vivientes, los actos que presentan caracteres de voluntariedad, los que parecen ligados a una conciencia más o menos clara, son actos que se enderezan a procurarse subsistencia el ser que los ejecuta ${ }^{31}$.

De esta manera, llegamos a la idea de conducta, es decir, de comportamiento aprendido. Por consiguiente, cuando hablamos de conducta, en ningún caso nos referimos a conductas reflejas o instintos, sino a aquellos movimientos que el organismo realiza en respuesta a las percepciones recibidas y a las relaciones que con ellas establece.

Como decíamos, los organismos heterótrofos tienen que desplazarse para buscar el alimento, razón fundamental por la que están dotados de un sistema perceptivomotor que les permite planificar, coordinar y ejecutar los movimientos. Así pues, la conducta de estos organismos consistirá en orientarse entre los diferentes grados de variabilidad del entorno, para seleccionar los mejores itinerarios que conduzcan a saciar el apetito. La elección de un derrotero u otro exige un conocimiento del medio, constituyendo el elegir bien, una importante ventaja adaptativa ${ }^{32}$.

\section{EL CONOCIMIENTO SE ADQUIERE}

Las ideas que acabamos de esbozar vienen también avaladas porque, según Turró, no hay conocimiento innato. En efecto, gracias a las detalladas observaciones que había realizado a animales recién nacidos, gracias a su condición de veterinario, sabía que no hay conocimiento instintivo, como dice Miguel Siguán:

30 J.B. Fuentes, E. Quiroga, F. Muñoz, Una primera aproximación alas posibilidades de desarrollo de la teoría del origen trófico del conocimiento de Ramón Turró, "Revista de Historia de la Psicología” 2005, núm. 2-3, pp. 81-189.

31 M. de Unamuno, Del sentimiento trágico..., p. 93.

32 J.B. Fuentes, E. Quiroga, F. Muñoz, op. cit. 
Pobrane z czasopisma Annales I - Philosophy and Sociology http://philosophia.annales.umcs.pl Data: 26/04/2023 15:36:46

El origen del conocimiento según Ramón Turró como comienzo psicológico...

69

Turró sabe que no hay tal conocimiento instintivo porque ha pasado horas observando a los polluelos acabados de nacer y ha visto que de entrada picotean al azar y sólo al cabo del tiempo aprenden a picotear únicamente los granos del suelo. Y ha visto igualmente que los terneros acabados de nacer no aciertan al primer intento con la ubre de la madre y han de multiplicar sus ensayos ${ }^{33}$.

Esta cuestión es central, ya que, como observa Juan B. Fuentes en la importante nota 49 de su trabajo, "si toda conducta es abstracta, de acuerdo con la condición abstracta del conocimiento que le es inherente, ello quiere decir, sencillamente, que no hay instintos" 34 .

En efecto, no hay instintos sobre el conocimiento del alimento, pero lo que sí es innato son los sentimientos de hambre y de saciedad. La propensión a alimentarse que experimenta el organismo y el impulso que le pone en marcha son innatos. Por ejemplo, en el recién nacido que se agarra al pezón de la madre, "Lo que hay aquí de innato o preestablecido es el impulso que mueve a la prensión; mas los conocimientos que de esta prensión resultan, son hijos de la experiencia y no de intuiciones originales" 35 .

Turró, igual que Iván Pávlov trabajará con perros, pero a diferencia de éste, estudiará solamente a perros recién nacidos, los cuales no están "contaminados" con la experiencia vital o biografía de cada animal. Ciertamente, los experimentos realizados por Pávlov a los perros, ejemplifican con claridad la importante influencia que ejerce en la conducta la biografía del sujeto. Los animales de los experimentos ofrecían las mismas respuestas a los estímulos cuando estaban inconscientes, porque en esa situación, solamente respondían mediante sus médulas espinales, sin embargo, no reaccionaban igual a los mismos estímulos cuando estaban conscientes. En efecto, cuando los perros estaban despiertos y sus cerebros funcionaban normalmente, al detectar los estímulos, sus respuestas eran sensiblemente distintas, ya que no todos ellos habían vivido las mismas experiencias. $\mathrm{O}$, dicho de otra forma, sus biografías no eran iguales. De esta manera, Pávlov se dio cuenta de que los animales aprenden de sus propias experiencias, es decir, que el conocimiento no reside exclusivamente en cuestiones fisicalistas, sino más bien en cuestiones psicológicas o conductuales. De ahí su gran descubrimiento: el condicionamiento clásico. A Turró, por su parte, no le interesa quedarse en la mera investigación de los mecanismos del reflejo condicionado, sino elaborar una teoría genética del conocimiento.

\footnotetext{
33 M. Siguan, op. cit., p. 333.

34 J.B. Fuentes, op. cit., p. 43.

35 R. Turró, Orígenes del conocimiento..., p. 100.
} 


\section{PHRÓNESIS ANIMAL Y NUTRICIÓN EN ARISTÓTELES}

Los organismos conductuales tienen que decidir y decidir bien, lo cual exige un cierto grado de prudencia en la elección. No en vano, Aristóteles ${ }^{36}$ dice que algunos animales pueden ser prudentes por el modo en que realizan sus actos vitales. Como muestra López Gómez "Es posible hablar de phrónesis animal, no como una virtud intelectual exclusiva del hombre, sino como una excelencia relacionada con los actos vitales de los animales" ${ }^{37}$. Sin embargo, Fuentes ${ }^{38}$ advierte que es en otro libro de Aristóteles donde encontramos algo muy parecido a lo que apunta el profesor Turró: "Pero entonces nos es dado advertir que esta idea ya fue expresamente elaborada, y con todo cuidado, por Aristóteles, en particular en su tratado Acerca del Alma" ${ }^{39}$. En efecto, Aristóteles ya hace depender, como bien observa Fuentes, el conocimiento de la nutrición ${ }^{40}$ :

Así, pues, Aristóteles ha procedido deduciendo funcionalmente la sensación del movimiento, en la medida en que a su vez ha deducido funcionalmente el movimiento de la alimentación, es decir, de esa forma determinada de alimentación que exige el desplazamiento para obtener los alimentos que se encuentran distantes ${ }^{41}$.

Por consiguiente, todo organismo cognoscente tiene que ser heterótrofo $\mathrm{y}$, por tanto, debe tener una abertura que permita la ingesta de alimento, un sistema digestivo (por muy rudimentario que este pueda ser) y alguna suerte de aparato excretor que permita deshacerse del sobrante del proceso de digestión. Por ejemplo, un ser protista unicelular como la ameba cumpliría con estos requisitos, ya que se desplaza mediante la polarización de actina y fagocita plantas y animales microscópicos ${ }^{42}$. Ahora bien, aunque tales organismos tengan un incipiente sistema perceptivo que les permite orientarse por el entorno hacia el alimento, no podemos decir que conozcan. En efecto, para que el organismo pueda decidir qué camino escoger y qué alimento ingerir, tiene que tener una percepción sensorial de lo distante y no meramente por contacto. Es decir, tiene que haber "vinculación sensorial perceptiva con los alrededores geográficos remotos del

36 Aristóteles, Investigación sobre los animales, Madrid 1992.

37 C. López Gómez, Inteligencia animal en Aristóteles, "Discusiones Filosóficas” 2009, núm. 15 , p. 81 .

38 J.B. Fuentes, op. cit.

39 Ibídem, p. 30.

40 A este respecto, véase el Capítulo cuarto del Libro segundo de Aristóteles (Acerca del alma, Madrid 2003).

${ }_{41}$ J.B. Fuentes, op. cit., pp. 32-33.

42 W. Müller-Esterl, Bioquímica - Fundamentos para Medicina y Ciencias de la Vida, Barcelona 2008. 
Pobrane z czasopisma Annales I - Philosophy and Sociology http://philosophia.annales.umcs.pl Data: 26/04/2023 15:36:46

El origen del conocimiento según Ramón Turró como comienzo psicológico...

organismo" ${ }^{93}$. Por tanto, los organismos cognoscentes son organismos sensoriomotores ya que se orientan mediante la sensibilidad o percepción, exhibiendo de esta manera un comportamiento o una conducta y no una trayectoria errática o azarosa.

A esto hay que añadir que toda percepción, es decir, tener algún tipo de representación de lo distante, de lo que no está en contacto directo, es una abstracción cognoscitivamente configurada:

Por lo demás, y por fin, convendrá recordar que ya fue Aristóteles quien, como hemos visto, supo entender que la percepción sensorial de los organismos sensorio-motores es efectivamente abstracta, es decir, que consiste en la operación de "abstraer" la "forma" o la "cualidad" "sensible" de la "materia individual" - al objeto, en efecto, de que el organismo pueda tener cognoscitivamente presentes, mientras se desplaza hacia ellos, los alrededores remotos con los que debe llegar a contactar para alimentarse, y de este modo pueda orientar cognoscitivamente dichos desplazamientos ${ }^{44}$.

\section{CONCLUSIONES}

Como apunta Miguel de Unamuno, Ramón Turró lleva a cabo una teoría psicológica de la génesis del conocimiento. Por eso, las ideas del profesor Turró, acerca de cómo comienza el conocimiento, no son incompatibles con la teoría kantiana, sino más bien complementarias. Ambas teorías, no tratan de dos caras diferentes del conocimiento, sino de dos momentos claramente diferenciados. En el orden psicológico o temporal, el conocimiento comienza como muestra Ramón Turró. Pero en el orden lógico-epistemológico, si se quiere preservar la necesidad y la universalidad de la ciencia, ha de originarse como expresa el apriorismo de Immanuel Kant.

Así pues, la sensación de hambre se debe al gasto energético que tiene el medio interno debido a la alimentación de las células del organismo. Por consiguiente, el impuso trófico sería, usando la terminología kantiana, una anticipación de la percepción. Podemos decir, de manera general, que los organismos proceden conforme a aquello que decía Berkeley ${ }^{45}$ : esse est percipi, ya que, en principio, las sustancias externas solamente representan aquello que les falta para nutrirse. De esta manera, resulta que los organismos interpretan las percepciones, en virtud de un proceso inductivo, como la materia del conocimiento. Dicho de otra forma, la creencia en que las cosas existen fuera de nosotros consiste en la conexión causal entre la excitación trófica, la comida, los movimientos necesarios

\footnotetext{
43 J.B. Fuentes, op. cit., p. 34.

44 Ibidem, p. 43.

45 G. Berkeley, Tratado sobre los principios del conocimiento humano, Madrid 1992.
} 
para obtenerla y la satisfacción de tal impulso. Por tanto, resulta que los esfuerzos que tiene que realizar un organismo para saciar su apetito, son los que van a determinar tanto la existencia de los objetos externos, como del espacio en el que se establecen las relaciones causales y de acción recíproca entre ellos; de lo contrario, no podría afrontar los retos que supone la obtención de la comida. Por consiguiente, será en el proceso descrito en el que el organismo conozca la existencia, tanto de su propio cuerpo, como de su espacio biológico propio, o si se prefiere, de su mundo circundante (Umwelt), como diría von Uexküll16 o Heidegger ${ }^{47}$.

Según lo dicho, el conocimiento es operatorio ya que opera conductualmente. Es decir, el sujeto se comporta conforme a lo que va aprendiendo. Así pues, según Turró, no podemos hablar de conocimiento instintivo. Toda conducta implica algún grado de abstracción en función de lo aprendido por el organismo en cuestión. Lo innato quedaría reducido a la pulsión trófica y a la calma producida por la satisfacción de ésta.

Por último, no hemos querido olvidar como ilustre precursor de las ideas turronianas a Aristóteles. Muy especialmente en lo que se refiere a la nutrición y al movimiento como aspectos necesarios en la génesis del conocimiento en su aspecto psicológico.

\section{BIBLIOGR AFÍA}

Aristóteles, Acerca del alma, Madrid 2003.

Aristóteles, Investigación sobre los animales, Madrid 1992.

Berkeley G., Tratado sobre los principios del conocimiento humano, Madrid 1992.

Fuentes J.B., La Teoría del origen trófico del conocimiento deRamón Turró: Un ensayo sobre su trasfondo histórico-filosóficoy sus posibilidades de desarrollo teórico en el sentido de una concepción (neo)aristotélica de la vida, "Psychologia Latina" 2010, núm. 1.

Fuentes J.B., Quiroga E., Muñoz F., Una primera aproximación alas posibilidades de desarrollo de la teoría del origen trófico del conocimiento de Ramón Turró, "Revista de Historia de la Psicología" 2005, núm. 2-3.

García Morente M., La filosofía de Kant: una introducción a la filosofía, Madrid 1975.

Heidegger M., Interpretaciones fenomenológicas sobre Aristóteles. Informe de la situación hermenéutica, Madrid 2002.

Kant I., Crítica de la razón pura, Madrid 2005.

López Gómez C., Inteligencia animal en Aristóteles, "Discusiones Filosóficas” 2009, núm. 15.

46 J. von Uexküll, Andanzas por los mundos circundantes de los animales y los hombres, Buenos Aires 2016.

47 M. Heidegger, Interpretaciones fenomenológicas sobre Aristóteles. Informe de la situación hermenéutica, Madrid 2002. 
López Molina A.M., Filosofía como reflexión sobre el sentimiento trágico de la vida, [en:] M. de Unamuno, Del sentimiento trágico de la vida en los hombres y en los pueblos, edición de A.M. López Molina, Madrid 2006.

Martín Cuenca E., Fundamentos de fisiología, Madrid 2006.

Müller-Esterl W., Bioquímica - Fundamentos para Medicina y Ciencias de la Vida, Barcelona 2008. Siguan M., Ideas psicológicas en la obra de Ramón Turró, "Revista de Historia de la Psicología" 1980, núm. 3-4.

Spinoza B., Ética, edición, traducción y notas por V. Peña, Madrid 2009.

Turró R., La base trófica de la inteligencia, Serie I, T. IV, Madrid 1918.

Turró R., Orígens del coneixement: la fam, Barcelona 1912.

Turró R., Orígenes del conocimiento: el hambre, Madrid 1921.

Uexküll J. von, Andanzas por los mundos circundantes de los animales y los hombres, Buenos Aires 2016.

Unamuno M. de, Del sentimiento trágico de la vida en los hombres y enlos pueblos, edición de A.M. López Molina, Madrid 2006.

Unamuno M. de, Prólogo, [en:] R. Turró, Orígenes del conocimiento. El hambre (5-16), Madrid 1921.

\section{SUMMARY}

The article begins by presenting the texts of Ramón Turró on the trophic origin of knowledge. After the introduction, these ideas of Turró are conceived as a complementary theory to the epistemology of Kant, exposed mainly in the Critique of the Pure Reason. Turro's theories, thus understood, would explain how knowledge begins in experience, while the epistemology of Kant would refer to the rational mechanisms that give universality and necessity to scientific knowledge. That is to say, Kant realizes an epistemological theory, whereas Turró carries out a psychological theory of the genesis of the knowledge. From this perspective, and based on some texts by Miguel de Unamuno, the article briefly analyzes concepts as fundamental as reality, existence, space, knowledge, instinct or behavior. In the final part, a brief reflection on the concepts of animal phronesis and nutrition in Aristotle is included, in which the Stagirite is postulated as a precursor of the ideas of Turró.

Keywords: knowledge; trophic impulse; sensitivity; reality; existence

\section{STRESZCZENIE}

Artykuł rozpoczyna się od przedstawienia tekstów Ramóna Turró na temat troficznego pochodzenia wiedzy. Po wprowadzeniu autor niniejszego opracowania wskazuje, że idee Turró są pomyślane jako uzupełniająca teoria epistemologii Kanta, ujawniona głównie w Krytyce czystego rozumu. Rozumiane w ten sposób teorie Turró mogą wyjaśniać, w jaki sposób wiedza zaczyna się w doświadczeniu, podczas gdy w epistemologii Kanta odnoszą się do racjonalnych mechanizmów, które dają uniwersalność i konieczność wiedzy naukowej. Kant realizuje bowiem teorię epistemologiczną, natomiast Turró przeprowadza psychologiczną teorię genezy wiedzy. Z tej perspektywy, oraz w oparciu o teksty Miguela de Unamuno, autor artykułu pokrótce analizuje pojęcia tak fundamentalne, jak: rzeczywistość, istnienie, przestrzeń, wiedza, instynkt czy zachowanie. W końcowej części znajduje się krótka refleksja nad Arystotelesowskimi koncepcjami zwierzęcej phronesis i żywienia, w których Stagiryta może być uznany za prekursora idei Turró.

Slowa kluczowe: wiedza; umiejętności; impuls troficzny; wrażliwość; rzeczywistość; istnienie 
Pobrane z czasopisma Annales I - Philosophy and Sociology http://philosophia.annales.umcs.pl Data: 26/04/2023 15:36:46

\begin{abstract}
RESUMEN
El artículo comienza presentando los textos de Ramón Turró sobre el origen trófico del conocimiento. Tras la introducción, estas ideas de Turró se conciben como una teoría complementaria a la epistemología de Kant, expuesta principalmente en la Crítica de la razón Pura. Las teorías de Turró, así entendidas, explicarían cómo comienza el conocimiento en la experiencia; mientras que la epistemología de Kant, haría referencia a los mecanismos racionales que dotan de universalidad y necesidad al conocimiento científico. Es decir, Kant realiza una teoría epistemológica, mientras que Turró lleva a cabo una teoría psicológica de la génesis del conocimiento. Desde esa perspectiva, y apoyándonos en algunos textos de Miguel de Unamuno, el artículo analiza, sucintamente, conceptos tan fundamentales como el de realidad, existencia, espacio, conocimiento, instinto o conducta. En la parte final se incluye una breve reflexión acerca de los conceptos de phrónesis animal y nutrición en Aristóteles, en la que se postula al Estagirita como precursor de las ideas turronianas.
\end{abstract}

Palabras claves: conocimiento; impulso trófico; sensibilidad; realidad; existencia 